\title{
Impact of Bundle Type, Price Framing and Familiarity on Purchase Intention for the Bundle
}

\author{
Bari A. Harlam \\ UNIVERSITY OF RHODE ISLAND \\ Aradhna Krishna \\ Donald R. Lehmann \\ COLUMBIA UNIVERSITY \\ Carl Mela \\ UNIVERSTY OF NOTRE DAME
}

\begin{abstract}
Bundling of products is very prevalent in the marketplace. For example, travel packages include airfare, lodging, and a rental car. Considerable economic research has focused on the change in profits and consumer surplus that ensues if bundles are offered. There is relatively little research in marketing that deals with bundling, however. In this article we concentrate on some tactical issues of bundling, such as which types of products should be bundled, what price one can charge for the bundle, and how the price of the bundle should be presented to consumers to improve purchase intent. For example, we hypothesize that bundles composed of complements or equally priced goods will result in higher purchase intention. We also hypothesize that price increases will result in larger purchase intention changes than price decreases. Further, we expect that the presentation format for describing the price of the bundle will influence purchase intention in general, and, depending on the price level of the bundle, different presentation formats will result in higher purchase intention. Finally, we hypothesize that purchase intention changes associated with different price levels will be higher for subjects who are familiar with the products than for subjects who are less familiar with the products. We used an interactive computer experiment conducted among 83 Master of Business Administration (MBA) students to test our hypotheses. Our findings suggest that: (1) bundles composed of complements have a higher purchase intent than bundles of similar or unrelated products, (2) consumers are more sensitive to a bundle price increase than to a bundle price decrease of equal amounts, (3) different presentation formats for describing the price of the bundle influence purchase intention, and (4) more familiar subjects respond to different presentations of equivalent bundles in different ways than less familiar subjects. We did not find any support for the hypothesis that bundles composed of similarly priced items have higher purchase intent than bundles composed of unequally priced products. J BUSN RES 1995. 33.57-66
\end{abstract}

$\mathrm{B}$ undling, the joint pricing for sale of two or more products or components, is widely practiced in the marketplace. For example, travel packages include airfare, lodging, and

Address correspondence to Bari A. Harlam, Assistant Professor, Marketing Department, University of Rhode Island, 305 Ballentine Hall, Kingston, RI 02881. and a rental car (Dolan, 1987), music systems come as a bundle of the speakers, amplifier, stereo, and graphic equalizer, and razors and razor blades are routinely sold together. Although some bundles are obvious (e.g., razors and blades), orhers are far less so (e.g., Coca-cola and discount tickets to Great Adventure amusement park, Butterball turkey and discount on Florofax flowers, Kraft products' proof of purchases to receive a dinosaur version of the Pictionary game, Giant Eagle Grocers register tapes for a discount on an Apple Computer, and so on). Given the widespread use of bundles, it seems important to gain an understanding of what makes them work.

Considerable research has focused on bundling from an economic viewpoint. The major output of this work has been to explore the conditions under which bundling is an optimal strategy. This research suggest that the profitability of a bundling strategy is likely to be influenced by, among other things, customers' reservation prices for the component products (Adams and Yellen, 1976; Burstein, 1960; Schmalensee, 1984; Stigler, 1968; McAfee, McMillan, and Whinston, 1989; Telser, 1979). Schmalensee (1984) shows that bundling will be profitable when the SD for the reservation price of the bundle is less than the sum of the SD for the bundle components. Telser (1979) focuses on superadditivity between reservation prices of the bundle components or complementarity as reasons for profitability of bundling.

The decision to offer a bundle and the design of bundles are of obvious importance to marketers. There has been relatively little research in marketing dealing with bundling, however. Some research within marketing has focused on the optimality of bundling using an applied economic approach (Foster, 1992; Guiltinan, 1987; Hanson and Martin, 1990; Wilson, Weiss, and John, 1990). For example, Hanson and Martin (1990) provide a mixed integer linear program to select the products to be included in a firm's product line and to optimally price bundles and product components. Wilson et al. (1990) examine the conditions under which a firm should consider "unbundling" complete systems of components. Another stream 
of research has focused on measurement of preference for item collections using conjoint analysis (Green, Wind, and Jain, 1972; Green and Devita, 1974; Green and Wind, 1984).

Recent research (Dolan, 1987; Drumwright, 1992; Karlinsky and Farquar, 1988; Nagle, 1987) applies Kahneman and Tversky's prospect theory (1979) to generate an alternative behavioral explanation for bundling. According to Prospect Theory, consumers' utility functions are concave in gains and convex in losses. Also, the loss function is steeper than the gain function so that losses hurt more than gains help. Consequently, in as much as buyers view separate products in a bundle as distinct benefits (gains) for one price (loss), they would be more likely to buy products in a bundle than they would be to buy the products separately. Using an alternative interpretation of gains and losses, results from Kaicker and Bearden's (1993) research also suggest that consumers prefer bundled purchases in situations of mixed gains and losses.

Recent research by Yadav and Monroe (1993) also examines behavioral aspects of bundling. Their work considers buyers' perceptions of savings when they evaluate a bundle offer. Yadav and Monroe (1993) investigate a mixed-bundling strategy where buyers can either purchase the bundle or the individual items. Their research tests the relative effects of savings offered on individual items and of savings offered directly on a bundle of items. Their findings suggest that buyers' perceptions of savings are a combination of perceived additional savings on the bundle and perceived savings offered on the items if purchased separately.

We concentrate on more tactical issues associated with bundling strategies for promotion purposes. We ask questions such as what kinds of products should be bundled together, what price to charge for the bundle, and how to present the price of a bundle to make it attractive to consumers. Essentially, we take the point of view of a product manager. Assuming the product manager is considering including their product as part of a bundle, then two basic issues arise: (1) with what other type of product to bundle, and (2) how to present the price of the bundle. This article explores these issues using a computer survey-based methodology.

The remainder of the paper is organized as follows. In Section 2 we describe our hypotheses. Section 3 describes the experiment that was conducted to test the hypotheses and also describes the results. Section 4 discusses conclusions and future research implications of our results.

\section{Hypotheses}

We divide our hypotheses into four categories: (1) hypotheses pertaining to the composition of the bundle, specifically which types of products should be bundled, (2) the price to charge for the bundle given consumers' reservation prices for the component products, (3) the semantic presentation of the bundle, and (4) individual differences.

\section{Bundle Composition}

The selection of which products to bundle is obviously important to the success of the bundle. Here, we consider two dimensions along which product selection for a bundle may differ: complementary versus unrelated goods, and equal-priced products versus unequal-priced products.

Telser (1979) examined the profitability of bundling when the component products are complements rather than substitutes or unrelated products. He demonstrated that complementarity between products can cause bundling to be profitable. Gaeth et al. (1990) studied the relative effect of the primary product and the tie-in product on the evaluation of the bundle. They found that the separate evaluations of the two products are averaged to form overall evaluation for the bundle. Gaeth et al. also provide some empirical evidence that complementarity positively affects bundle reservations prices. This would imply that

H1: Bundles composed of complements will have a higher purchase intent than bundles of unrelated products.

Another important aspect of the products is the price difference or similarity between the products. If prices are very different, a bundle may be perceived as essentially one product with a "free" but inconsequential product thrown in (e.g., a computer and a $31 / 2$ " diskette). Hence, the price of the second product will be largely ignored. If, on the other hand, the prices are close to equal, the bundle will be considered to be a "real" one (e.g., a computer and a printer) and both product prices are relevant. Thus, we expect

H2: Bundles composed of equally priced goods will have a higher purchase intent than bundles of unequally priced products.

\section{Price Discount Level}

Our research considers three types of price levels or bundle prices: 'decrease', where the price of the bundle is less than the sum of the reservation prices for the product components of the bundle; 'same', where the price of the bundle is the same as the sum of the reservation prices for the product components of the bundle; and 'increase', where the price of the bundle is greater than the sum of the reservation prices for the product components in the bundle (single quotes denote a treatment condition). We consider price 'increases' based on prior research by Demsetz (1968). His research indicates that a consumer's reservation price for a bundle may be greater than the sum of the reservation prices for the component products due to transaction or information gathering cost savings incurred when purchasing a bundle.

Kahneman and Tversky's value function (1979) is steeper in losses than in gains implying that a loss of a specified amount makes the consumer lose more utility than a gain of the same amount makes him gain. Also, DeSarbo et al. (1987) find evidence of a differential response for price increases and price decreases. This suggests that 
H3: Changes in purchase intention due to a bundle price increase' will be larger than changes in purchase intention due to a bundle price 'decrease' of equal amounts relative to consumers' reservation prices for the product components of the bundle.

\section{Bundle Presentation}

Presentation or framing effects are now well established as a determinant of behavior (e.g., Puto, 1987). Hence, different ways of describing economically equivalent bundle offers (different semantic cues or different framing of the bundle) may affect evaluation of the bundle. Research by Kahneman and Tversky (1979) demonstrates that the salient decision frame in a judgment task, holding information content constant, can affect the choices made by consumers. Hence, economically equivalent deals may be evaluated differently depending on the way in which the bundle is presented.

Della Bitta, Monroe, and McGinnis (1981) found that presenting information as different combinations of sale price, regular price, percentage off, and dollar amount off resulted in different perceptions of the offer. Their research results indicated that stating the regular price with the dollar amount off was the most positively evaluated presentation. Barnes (1975) found significant differences in evaluation across the following three semantic cues: (1) special, \$__ (2) $25 \%$ off $\$ \_$_ (3) xxx's regular price $\$ \_$, sale price $\$ \_$. In Barnes' research, condition 3 was the most preferred presentation. Das (1992) experimentally examined the effect of the following four semantic price cues: (1) \$_ off; (2) 2 for $\$ \_$_ (3) _ $\%$ off; (4) Buy 1 , get 1 at _ price. She found support for the effect of semantic cues and that overall the " 2 for \$_ " and "Buy 1 , get 1 at _ _ price" were most effective across various price levels.

In the current research we focus on the following three forms of bundle presentations, which an examination of newspaper and magazine ads suggested were the most common

1. 'Together': Buy X and Y together at \$_. For example, buy the Sony VCR and Fuji Tapes for $\$ 399$

2. 'Separate': Buy $X$ at $\$$ _ and $Y$ at $\$$ _ if you buy the bundle. For example, buy the Sony VCR for $\$ 379$ and the Fuji Tapes for $\$ 20$.

3. 'Freebie': Buy $X$ at $\$$ _ get $Y$ for free. For example, buy the Sony VCR for $\$ 399$ and receive the Fuji Tapes for free.

Based on the literature on semantic cues discussed earlier, we expect that

$\mathrm{H} 4 \mathrm{a}$ : In general, the framing of the price of the bundle will affect purchase intent.

Below we discuss several more specific hypothesis related to price level for the bundle offer.

Das (1992) found that the semantic effect of the price deal was moderated by the price of the product. So, for example, the "Save $\$$ "frame was particularly effective at high price levels but not at low price levels. We also expect that the presentation of the bundle will be moderated by the overall price level of the bundle.

$\mathrm{H} 4 \mathrm{~b}$ : There will be an interaction between framing of the bundle and the price level of the bundle such that the framing of the bundle will lead to larger purchase intention changes at high price levels and smaller purchase intention changes at low price levels.

Further, when the price of the bundle 'decreases,' there will be one large decrease in price presented to consumers in the 'together' frame versus two smaller decreases presented to them in the 'separate' frame. This may make the 'decrease' in the bundle price more salient (Tversky and Kahneman, 1974) to consumers in the 'together' frame and may have a larger effect on their purchase intent. This effect would also be suggested by assimilation-contrast theory (Sherif and Hovland, 1961). Further, Gabor and Granger (1964) have suggested that there is a price range internal to consumers called a latitude of acceptance that is a range of acceptable prices. A price that is outside the range is contrasted to the acceptable price range and becomes noticeable. This concept is also supported by Weber's Law (see Monroe, 1971). Monroe (1971) has validated the theory in laboratory experiments. Based on this theory, a larger change in price is more likely to lie outside the latitude of acceptance and therefore be more noticeable to consumers. Thus, because both separate prices decreases could be within tolerance ranges of normal prices but the overall price might be outside the tolerance range for the total price, one large decrease in price in the 'together' frame will be more noticeable than two smaller decreases in the 'separate' frame, and therefore lead to a greater purchase intent for the bundle.

Interestingly, Thaler's theory that consumers aggregate losses and segregate gains (Thaler, 1985) might be expected to work opposite to the previously mentioned theories. Mazumdar and Jun (1992) present hypotheses consistent with this alternative interpretation in their research. This theory suggests that two small gains are better than one large one that is equal to the sum of the two smaller gains. Thaler's theory assumes that the losses and gains are perceptible to consumers, however. Two smaller increases or decreases in the price of a bundle are, in general, less likely to be noticed by consumers due to the relatively small absolute changes. The related hypotheses in Mazumdar and Jun (1992) are formulated for the comparison of consumers' preferences for bundled or component offerings. Their research forces consumers to recognize that the presented prices lie outside of their price expectations. In our research, however, realistic but relatively small price changes are used ( $20 \%$ decreases and increases relative to individual reservation prices). Further, price offerings are simply stated for consumers and whether or not the prices are increased or decreased is not highlighted for consumers. Thus, in our research setting we believe that when the price changes are aggregated across the product components for the bundle, they become more easily perceived. Therefore, we expect a stronger salience effect and 
assimilation-contrast effect than segregation of gains effect. Hence, we hypothesize the following:

H4c: Presenting the price for the bundle 'together' will lead to higher purchase intention than presenting 'separate' prices when the price of the bundle 'decreases.'

When the price of the bundle is the 'same' as the sum of the individual prices, the bundle in the 'separate' frame is similar to the pure components (no bundle) scenario. Hence,

$\mathrm{H} 4 \mathrm{~d}$ : When the price of the bundle is the 'same,' the bundle in the 'separate' frame will have the lowest purchase intention

When the price of the bundle 'increases,' there will be one large increase in price presented to consumers in the 'together' frame versus two smaller increases in the 'separate' frame. This may make the 'increase' in bundle price in the 'together' frame more salient (Tversky and Kahneman, 1974) to consumers and may also have a greater chance of lying outside their latitude of acceptance (Sherif and Hovland, 1961). Thus, it may have a larger negative effect on their purchase intent.

$\mathrm{H} 4 \mathrm{e}$ : Presenting the prices 'separately' for the bundle components will lead to higher purchase intention than presenting the price of the bundle 'together' when the bundle price 'increases.'

\section{Familiarity}

A plethora of individual difference variables exist that might be related to the purchase intent for bundles. Here we focus on a single one, namely familiarity of subjects with items in the bundle. Knowledge, familiarity, and expertise have important impact on information search, recall, and utilization (Brucks, 1985; Alba and Hutchinson, 1987)

Sujan (1985) and Hoch and $\mathrm{Ha}$ (1986) have demonstrated that experts attend to information differently. Based on this research, insofar as expert consumers are more familiar with the items, they might be more aware of price information and have a greater confidence in their pricing judgments. Hence, consumers familiar with the component products would be more likely to know the prices of the component items than unfamiliar consumers. Consequently, familiar consumers may be more sensitive to the price of the bundle. Further, Biswas (1992) has shown that brand familiarity exerts a strong influence on consumer price perceptions in a context involving single products. Hence, we propose that

H5: Purchase intention changes for both 'increases' and 'decreases' in the price of the bundle will be larger for subjects familiar with the products than unfamiliar subjects.

\section{Method}

\section{Overview}

We could not find enough variance in the marketplace for some factors (e.g., framing and price level of bundle) within the same product category to run a field study. Therefore, we used an interactive computer experiment to test the hypotheses. Computer-simulated shopping experiments have been used by several other researchers (e.g., Buyukkurt, 1986; Kahn and Louie, 1986; Kahn and Raju, 1991; Krishna, 1991; Meyer and Assuncao, 1990). Burke et al. (1992) and Simonson and Winer (1990) show that computer-simulated laboratory purchases closely parallel real shopping trip behavior

We manipulated the following variables: COMPLEMENT (yes/no), price SIMILARity (equal/unequal), price LEVEL of the bundle ('decrease'/'same'/'increase'), FRAME of the bundle ('together'/'separate'/freebie'). We included DURABLE in addition to the variables suggested by the hypotheses (COMPLEMENT, SIMILARity, price LEVEL, and FRAME) as an exploratory variable. Though we have no strong theory to support it, our intuition was that subjects would pay more attention to price changes for durable goods both because they would have to "live" with their choices longer and because they tend to be more expensive, hence increasing involvement. This yielded a $2 \times 2 \times$ $2 \times 3 \times 3$ between-subjects and within-subjects design. The product variables (COMPLEMENT, DURABLE, SIMILAR) were manipulated within subjects. The other two factors (LEVEL and FRAME) were manipulated between subjects

\section{Pretest Determined Stimuli}

We examined bundles that were pairs of products. We restricted ourselves to two-item bundles because: (a) they are most common in the marketplace, and (b) it simplifies the respondent and analyst tasks.

We conducted pretests to identify product pairs to represent the desired manipulations in terms of equal price versus unequal price and complements versus unrelated products. Twenty pairs of products (bundles) were rated on 7-point scales for both factors. The scales for equal versus unequal prices went from extremely different (1) to extremely similar (7). The scale for complement versus unrelated went from extremely unrelated (1) to extremely complementary (7). We selected the eight bundles that best fit (had the most extreme values for) the eight required product treatments [DURABLE $(2) \times$ COMPLEMENT (2) $\times$ price SIMILARity (2)] for use in the experiment. For example, among the durable product pairs used in our pretest, the largest difference between the pretest price SIMILARity evaluations resulted between the following two pairs, Sony VCR and Panasonic Television versus Sony VCR and Fuji Tapes. The bundle pairs used in our experiment are listed in Table 1

\section{Procedure}

Eighty-three subjects were recruited to participate in the experiment. Subjects were MBA students who voluntarily agreed to take part in the experiment. Each subject was paid $\$ 5.00$. Subjects worked independently.

Each subject received a diskette and written instructions for running the experiment. During the computerized experiment, subjects answered a number of questions in the following order:

1. Reservation price for the separate products: What is the 
Table 1. Product Bundles Used in the Experiment

\begin{tabular}{lll}
\hline & \multicolumn{1}{c}{ Equal Price } & Unequal Price \\
\hline $\begin{array}{l}\text { Durables } \\
\text { Complements } \\
\text { Unrelated }\end{array}$ & $\begin{array}{l}\text { Sony VCR and Panasonic TV } \\
\text { Sony VCR and Seiko watch }\end{array}$ & $\begin{array}{l}\text { Sony VCR and Fuji tapes } \\
\text { Sondurables } \\
\begin{array}{l}\text { Complements } \\
\text { Unrelated }\end{array}\end{array}$ \\
\hline
\end{tabular}

most you would be willing to pay for ___ ? (Subjects were asked separate questions for each of the 10 individual products.)

2. Familiarity for the separate products: Please indicate how familiar you are with ___ ? (Subjects were asked separate questions for each of the 10 individual products.)

3. Purchase intent for the separate products: How likely would you be to purchase ___ at the price you provided earlier of ___ ? (Subjects were asked separate questions for each of the 10 individual products. Answers to question 1 were inserted for the prices.)

4. Distraction tasks, which took approximately 4 minutes.

5. Purchase intent for the bundle: How likely would you be to purchase the following__ ? (Subjects were asked separate questions for each of the eight bundles. The undiscounted price of the bundle was equal to the sum of the prices for the separate products elicited in Question 1. The price discount levels and framing manipulations varied across subjects for these questions.)

6. How complementary do you feel ___ is with ___ ? (This question was asked for confirmation purposes only. Subjects were asked separate questions for each of the eight bundles. Complementary levels were manipulated in the bundle composition within subjects based on the pretest discussed previously.)

7. How similar do you feel the price charged for _____ is to the price charged for ___ ? (This question was asked for confirmation purposes only. Subjects were asked separate questions for each of the eight bundles. Price similarity levels were manipulated in the bundle composition within subjects based on the pretest discussed above.)

8. Various demographic questions.

\section{Measures and Manipulations}

COMPLEMENT (yes/no), price SIMILARity (yes/no), and DURABLE (yes/no) were manipulated based on the pretest discussed above, producing the eight different bundles shown in Table 1. Notice that we kept one product common across four cells (equal/unequal products and complement/unrelated products) for both durables and nondurables. Hence, the product held constant for durables is Sony VCR and for nondurables is Neutrogena Shampoo.

Consumers provided reservation prices for each of the ten products in Table 1. The self-explicated reservation price is defined in this study as the most they are willing to pay for the product. The reservation prices for the separate products were used to construct the bundle price presented later in the experiment. The bundle price LEVEL was either equal to the sum of the reservation price for the component products ('same'), $20 \%$ less ('decrease'), or $20 \%$ more ('increase'). We chose $20 \%$ because it is a common discount level for sales. We chose a percentage rather than a dollar amount to allow for easier comparison across different bundles.

The three-price FRAME bundles we used are: 'together', 'separate, and 'freebie.

A 7-point scale measured the purchase INTENT for the individual products and the bundle $(1=$ definitely would not buy, $7=$ definitely would buy). A 7 -point scale also measured consumers' familiarity with each product $(1=$ not at all familiar, 7 = extremely familiar). We used the arithmetic mean of the familiarity for each of the component products in the bundle as the measure for bundle FAMILIARity. Other possible measures include the familiarity score for the more familiar product or the familiarity score for the less familiar product. We chose to use the arithmetic mean of the separate familiarity scores because it is one way to reflect subjects' familiarity with both components of the bundle in the overall bundle familiarity measure.

\section{Results}

We used Analysis of Variance (ANOVA) to analyze the experiment. The dependent variable was purchase INTENT for the bundle. The independent variables were COMPLEMENT (yes/ no), DURABLE (yes/no), price SIMILARity ('equal'/unequal'), price LEVEL of bundle ('same'/'decrease'/'increase'), and FRAME of bundle ('together'/'separate'/'freebie') plus two-way interactions between these variables. In addition, we also had five covariates: FAMILIARity, purchase intent for component 1 (PII), purchase intent for component 2 (PI2), FAMIN (familiarity $x$ dummy variable for 'increase' in the price of the bundle), and FAMDE (familiarity $\times$ dummy variable for 'decrease' in the price of the bundle). We did not find any differences in evaluation of bundles for durable versus nondurable goods $(p>0.5)$. Thus, the findings appear to apply across different classes of goods, and we report results aggregated across both durable and nondurable goods

\section{Manipulation Checks}

We expect that the purchase intent for the bundle will be related to the purchase intent for the component products. Green and 
Table 2. ANOVA Results

\begin{tabular}{|c|c|c|c|c|}
\hline Source of Variation & $\begin{array}{l}\text { Sum of } \\
\text { Squares }\end{array}$ & DF & $F$ & $\begin{array}{c}\text { Significance } \\
\text { of } F\end{array}$ \\
\hline $\begin{array}{l}\text { Covariates } \\
\text { FAMILIAR } \\
\text { PI1 } \\
\text { PI2 } \\
\text { FAMIN }^{\mathrm{b}} \\
\text { FAMDE }^{\mathrm{c}}\end{array}$ & $\begin{array}{r}670.71 \\
0.53 \\
20.73 \\
86.58 \\
218.72 \\
52.18\end{array}$ & $\begin{array}{l}5 \\
1 \\
1 \\
1 \\
1 \\
1\end{array}$ & $\begin{array}{r}43.833 \\
0.173 \\
6.774 \\
28.292 \\
71.471 \\
17.052\end{array}$ & $\begin{array}{l}0.000 \\
0.678 \\
0.009 \\
0.000 \\
0.000 \\
0.000\end{array}$ \\
\hline $\begin{array}{l}\text { Main effects } \\
\text { FRAME } \\
\text { Price LEVEL of Bundle } \\
\text { COMPLEMENT } \\
\text { Price SIMILARity } \\
\text { DURABLE }\end{array}$ & $\begin{array}{r}130.42 \\
16.18 \\
43.38 \\
76.45 \\
0.54 \\
0.30\end{array}$ & $\begin{array}{l}7 \\
2 \\
2 \\
1 \\
1 \\
1\end{array}$ & $\begin{array}{r}6.088 \\
2.643 \\
7.088 \\
24.982 \\
0.177 \\
0.098\end{array}$ & $\begin{array}{l}0.000 \\
0.072 \\
0.001 \\
0.000 \\
0.674 \\
0.754\end{array}$ \\
\hline $\begin{array}{l}\text { 2-Way interactions } \\
\text { FRAME } \times \text { price LEVEL of Bundle } \\
\text { FRAME } \times \text { COMPLEMENT } \\
\text { FRAME } \times \text { Price SIMILARity } \\
\text { FRAME } \times \text { DURABLE } \\
\text { Price LEVEL of Bundle } \times \text { COMPLEMENT } \\
\text { Price LEVEL of Bundle } \times \text { Price SIMILARity } \\
\text { Price LEVEL of Bundle } \times \text { DURABLE } \\
\text { COMPLEMENT } \times \text { Price SIMILARity } \\
\text { COMPLEMENT } \times \text { DURABLE } \\
\text { Price SIMILARity } \times \text { DURABLE }\end{array}$ & $\begin{array}{r}86.70 \\
40.28 \\
9.07 \\
2.99 \\
0.65 \\
15.07 \\
3.38 \\
13.85 \\
0.73 \\
1.79 \\
0.03\end{array}$ & $\begin{array}{r}19 \\
4 \\
2 \\
2 \\
2 \\
2 \\
2 \\
2 \\
1 \\
1 \\
1\end{array}$ & $\begin{array}{l}1.491 \\
3.290 \\
1.483 \\
0.489 \\
0.106 \\
2.463 \\
0.552 \\
2.263 \\
0.237 \\
0.585 \\
0.009\end{array}$ & $\begin{array}{l}0.082 \\
0.011 \\
0.228 \\
0.614 \\
0.900 \\
0.086 \\
0.576 \\
0.105 \\
0.626 \\
0.445 \\
0.924\end{array}$ \\
\hline $\begin{array}{l}\text { Explained } \\
\text { Residual } \\
\text { Total }\end{array}$ & $\begin{array}{r}887.83 \\
1934.08 \\
2821.90\end{array}$ & $\begin{array}{r}31 \\
632 \\
663\end{array}$ & 9.359 & 0.000 \\
\hline
\end{tabular}

${ }^{a}$ PII - Purchase Intent for lst component of bundle.

${ }^{b}$ FAMIN - Familiarity by dummy for increase in price of bundle.

FAMDE - Familiarity by dummy for decrease in price of bundle

Wind (1984) found that the preference for a bundle is an increasing function of the preference for the components of the bundle. Gaeth et al. (1990) found that each product's purchase intent contributes equally to the bundle purchase intent. Therefore, we expect that higher purchase intent for an item in the bundle (PIl or PI2) will result in higher purchase INTENT for the bundle. ANOVA results suggest that there is a significant main effect for both purchase intent for product $1[\mathrm{~F}(1,632)$ $=6.77, p<0.01]$ and purchase intent for product $2[\mathrm{~F}(1,632)$

$=28.29, p<0.01$ ] (see Table 2).

Further, the demand function for normal goods implies that the lower the price of the bundle, the higher the purchase intent for the bundle. A lower price LEVEL of the bundle was associated with a higher purchase INTENT for the bundle, as expected. ANOVA revealed a significant main effect for price LEVEL of the bundle $[\mathrm{F}(1,632)=7.09, p<0.01]$.

The results for the relationship between bundle purchase INTENT and (1) purchase intention for the component products and (2) price discount LEVEL serve to give us increased confidence that subjects were paying attention to the task.

\section{Bundle Composition}

We considered two dimensions along which product selection for a bundle may differ: complements versus unrelated, and equal-priced products versus unequal-priced products.

ANOVA results reveal a significant main effect for COMPLEMENT $[F(1,632)=24.98, p<0.01]$. Bundles composed of COMPLEMENTs had a higher purchase INTENT than bundles of unrelated products ( $\mathrm{H} 1,4.14$ versus 3.44$)$. Hence hypothesis $\mathrm{Hl}$ is supported.

H2 stated that bundles composed of SIMILARly priced items will have significantly higher purchase INTENT than bundles of unequally priced products. We did not find a significant main effect for price SIMILARity ( $M=3.77$ for equal priced goods and 3.81 for unequal priced goods; $p>0.5$ ), thus failing to support $\mathrm{H} 2$.

\section{Price Discount LEVEL}

The third hypothesis pertained to the price discount LEVEL for the bundle. Subjects were more sensitive to a bundle price 
'increase' than to a bundle price 'decrease' of equal amounts (H3). The mean purchase INTENT is 4.07 for the 'same' price of bundle condition, 4.73 for the 'decrease' condition, and 2.58 for the 'increase' condition. The difference between 'same' and 'increase' is significantly larger than the difference between 'same' and 'decrease'. A nested model test for nonlinearity versus linearity in the curve linking purchase intent to the three price LEVEL of the bundle conditions is significant, showing that the curve is not linear $(p<0.01)$. Purchase intent is indeed more sensitive to price increases than to price decreases. Therefore, hypothesis $\mathrm{H} 3$ is supported

\section{Bundle Presentation}

According to $\mathrm{H} 4 \mathrm{a}$, in general the FRAME of the price of the bundle should affect purchase INTENT. We found a mildly significant main effect for FRAME of the bundle $[\mathrm{F}(2,632)=2.64$, $p<0.1$ ] with 'together' producing the highest purchase intent and 'separate' producing the lowest.

$\mathrm{H} 4 \mathrm{~b}$ stated that there would be an interaction between frame of the bundle and the price level of the bundle (FRAME $\times$ LEVEL). This interaction was found to be significant $[F(4,632)=$ $3.29, p<0.05$ ]. Cell means for purchase INTENT in the 9 FRAME $\times$ LEVEL bundle conditions are displayed in Figure 1 .

Presenting the price for the bundle 'together' was more effective than presenting 'separate' prices when the price of the bundle 'decreased' ( $\mathrm{H} 4 \mathrm{c})$. In Figure 1, we can see that when the price of the bundle is 'decreased', the highest purchase INTENT is for the 'together' condition. Contrast tests show that the difference between the purchase INTENT in the 'together' (5.30) and 'separate' cells (4.35) is significant $[\mathrm{F}(1,587)=8.3, p<0.01]$.

Also as hypothesized, when the price of the bundle was the 'same', the bundle in the 'separate' frame was the least preferred $(\mathrm{H} 4 \mathrm{~d})$. The cell means in Figure 1 show that when the price of the bundle is the 'same', the lowest purchase intent is for the 'separate' condition (mean purchase intent $=3.61$ ). Contrast tests show that the difference between the purchase INTENT in the 'separate' condition and the 'together' condition (4.24) is significant $[\mathrm{F}(1,587)=4.49, p<0.05]$, as is the difference between the 'separate' and the 'freebie' condition $[M=4.31$, $\mathrm{F}(1,587)=5.47, p<0.05]$.

There was no appreciable difference in impact when the price of the bundle was higher than the sum of the reservation prices. Apparently there is no good way to deliver bad news, contrary to $\mathrm{H} 4 \mathrm{e}$. Hence, FRAME makes a significant difference when the price of the bundle is the 'same' or is 'decreased' but not when it is 'increased'.

\section{Individual Differences}

Per H5, subjects' FAMILIARity will have an effect on their purchase INTENT so that more familiar subjects will be more sensitive to the price LEVEL of the bundle than less familiar subjects. We found significant effects for FAMIN (familiarity $x$ dummy for INCREASE, $F(1,632)=71.47, p<0.01]$ and for FAMDE [familiarity $\times$ dummy for DECREASE $F(1,632)=17.05$, $p<0.01]$. To determine the effect of familiarity on purchase intent in each of the bundle price conditions, we did a median split of FAMILIARity (the median was 4.5), and then computed cell means for purchase INTENT in the 6 FAMILIARity $\times$ price LEVEL of bundle conditions. Table 3 displays these cell means.

We can see in Table 3 that a 'decrease' in the bundle price (from being the 'same') seems to make a large difference in purchase intent for the more familiar consumers. Purchase intent increases significantly $[F(1,206)=9.56, p<0.01]$ from 3.9 to 5.08. For less familiar consumers, however, a 'decrease' in bundle price seems to make no significant difference ( 4.48 versus $4.22, p>0.3$ ). This suggests that the overall result that we obtained for a 'decrease' in bundle price is attributed to familiar consumers, and that it would make little difference to less familiar consumers if the price of the bundle was 'decreased.' As far as an 'increase' in the price of the bundle is concerned, it

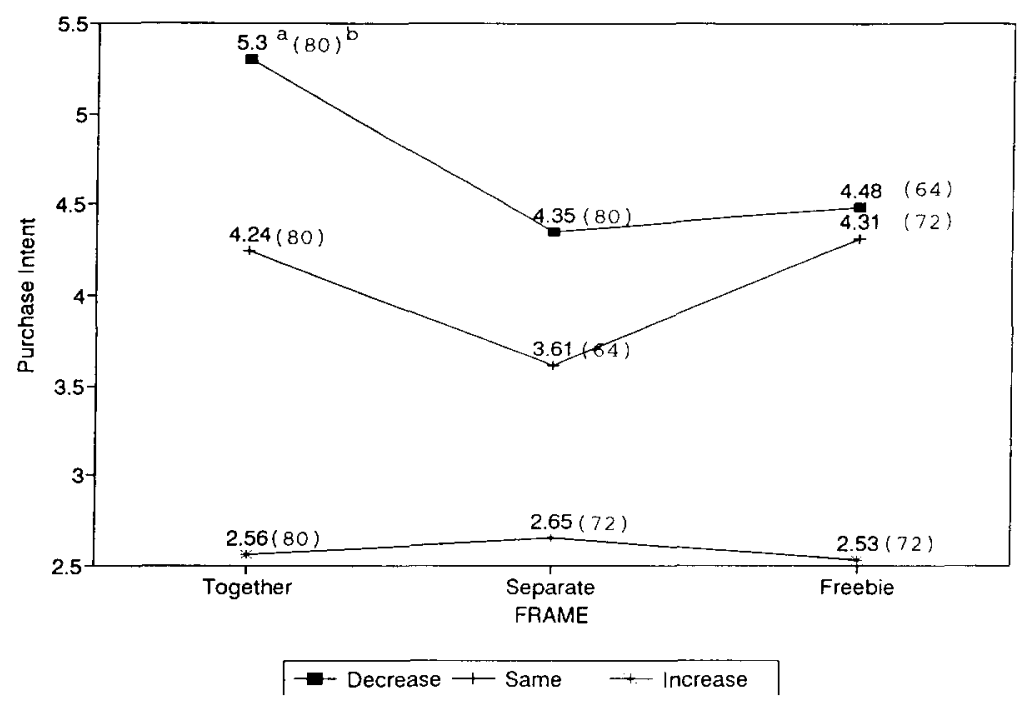

Figure 1. Price LEVEL and FRAME interaction. ${ }^{a}$ Mean purchase intent for the bundle. ${ }^{b}$ Number of observations. 
Table 3. Effect of Familiarity on Purchase Intent for the Bundle

\begin{tabular}{lcc}
\hline $\begin{array}{l}\text { Price LEVEL of } \\
\text { Bundle }\end{array}$ & $\begin{array}{c}\text { Low } \\
\text { FAMILIARity }\end{array}$ & $\begin{array}{c}\text { High } \\
\text { FAMILIARity }\end{array}$ \\
\hline Decrease & $4.48^{\mathrm{a}}$ & 5.08 \\
& $1.91^{\mathrm{b}}$ & 2.01 \\
$(13)^{\mathrm{c}}$ & $(93)$ \\
Same & 4.22 & 3.90 \\
& 2.02 & 1.98 \\
& $(116)$ & $(100)$ \\
Increase & 2.54 & 2.64 \\
& 1.55 & 1.61 \\
& $(138)$ & $(86)$ \\
\hline
\end{tabular}

${ }^{a}$ Mean purchase intent for the bundle.

bSD.

c Number of observations.

seems to affect both sets of consumers similarly. The purchase intent for both sets of consumers reduces substantially (to 2.54 for less familiar and to 2.64 for more familiar; $p<0.01$ for both). The cause of this asymmetric effect is unclear and deserves further study.

\section{Other Findings}

We also found a significant interaction for price LEVEL of bundle $\times$ COMPLEMENT $[F(2,632)=2.46, p<0.1]$. On observing the cell means for the 6 COMPLEMENT versus price LEVEL of bundle combinations we find that price 'increase' has a strong negative impact, regardless of whether the products are COMPLEMENTs; however the 'decrease' is more dramatic for complementary items.

Thus, overall we found that the level of complementarity affects bundle attractiveness, consumers are more sensitive to bundle price increases than price decreases, and that presentation of economically equivalent bundles in different ways affects purchase intent for the bundle. Further, we found that the effects of increase or decrease in the price of the bundle are moderated by familiarity.

\section{Summary and Implications}

Our findings raise some important issues to be considered by manufacturers involved in joint selling and promotion efforts. For example:

1. Our finding that bundles composed of compliments have a higher purchase intent than bundles of similar or unrelated products suggests that when manufacturers enter into bundling arrangements, they should ensure that potential consumers consider the component products to be complimentary. Future research might investigate various definitions of complements and the relative success of bundles based on the different definitions. For example, complements can be based on usage occasion, perceived relationships in manufacturing (Aaker and Keller, 1990 define this as "TRANSFER"), and the like.
2. Consumers are more sensitive to a bundle price 'increase' than to a bundle price 'decrease' of equal amounts. This finding suggests that consumers are not willing to pay a premium for transaction cost savings offered by bundles; however, transaction costs were not salient in our experiment. Therefore, future research should assess price increases relative to transaction costs in a setting in which transaction costs are pronounced.

3. There is an interaction between framing of the bundle and the price level of the bundle offer. This finding suggests that manufacturers should pay close attention to the presentation semantics of their bundle offers when the bundle price is less than or equal to the sum of the reservation prices for the products. Specifically, when bundle prices are below the sum of the reservation prices, a single bundle price should be given. A single price or a single price with a "freebie" description of the second price works equally well when the bundle price equals the sum of the reservation prices. When prices are increased, however, framing has no impact; consumers simply do not buy.

4. More familiar consumers respond to different presentations of equivalent bundles in different ways than less familiar consumers. Also, more familiar consumers have a higher purchase intent for lower priced bundles than less familiar consumers. Our findings suggest, however, the manufacturers will be unable to convince either familiar or unfamiliar consumers to pay a premium for bundles.

\section{Limitations and Future Research}

This study has a number of limitations that suggest directions for future research. First this research uses a laboratory experiment and, therefore, it has limited external validity. Bundles were presented on a computer screen rather than in real life. Research suggests that we might expect a smaller effect of price when a more complex store environment (i.e., busy aisles, many shelf facings, etc.) is present (Burke et al., 1992). Our findings need to be replicated in a field study before any strong conclusions can be drawn. Second, the data on familiarity were self-reports and, thus, it would be valuable to validate the study findings by using more objective familiarity measures. Third, our sample included only MBA students and, as a result, it would also be valuable to replicate our study using a more representative sample of customers.

Our study suggests many avenues for extensions. In the study, we only used bundles composed of two items, and it would be interesting to see how the results generalize to bundles of three or more items. Research by Yadav and Grewal (1993) is underway that explores consumers' biases when estimating the reference price of a bundle when the number of items in the bundle increases. Further, in our research, only a few bundles were actually used and it is conceivable that the results to some extent are idiosyncratic to the particular items involved. Another interesting extension would be to compare complemen- 
tary bundles of same versus different branded products (i.e., two Panasonics versus a Hitachi and a Toshiba) to see if the same brand connotes compatibility and hence greater compatibility. Also, we focused on reservation prices and not retail prices. Although the two were generally close empirically, and retail price is a determinant of reservation price, future research might seek to disentangle their effects. Finally, future work might concentrate on exploring the reasons for differences between high and low familiarity subjects in their reaction to price increases and decreases.

In summary, it matters what products are bundled together. Further, $20 \%$ price decreases have significant impact on purchase intent and the impact is most favorable when a single bundle price is presented. Interestingly, price decreases are effective only for familiar customers (which makes sense) but price increases have an impact on both familiar and unfamiliar customers, an asymmetry worthy of further investigation. It is hoped that future research can both corroborate and expand on these findings.

\section{References}

Aaker, David, A., and Keller, Kevin Lane, Consumer Evaluations of Brand Extensions. J. Marketing 54 (January 1980): 27-41.

Adams, William J., and Yellen, Janet L., Commodity Bundling and the Burden of Monopoly. Q. J. Economics 90 (August 1976): 475-498.

Alba, Joseph W., and Hutchinson, J. Wesley, Dimensions of Consumer Expertise. J. Consumer Research 14 (March 1987): 411-454

Barnes, James G., Factors Influencing Consumer Reaction to Retail Newspaper "Sale" Advertising. Proceedings, Fall Educators' Conference, Chicago: American Marketing Association, (1975): 417-477.

Biswas, Abhijit, The Moderating Role of Brand Familiarity in Reference Price Perceptions. J. Business Research 25 (1992): 251-262.

Brucks, Merrie, The Effects of Product Class Knowledge on Information Search Behavior. J. Consumer Research 12 (June 1985): 1-16.

Burke, Raymond R., Harlam, Bari A., Kahn, Barbara E., and Lodish, Leonard M., Comparing Dynamic Consumer Choice in Real and Computer-simulated Environments. J. Consumer Research 19 (June 1992): 71-82.

Buyukkurt, B. Kemal, Integration of Serially Sampled Price Information: Modelling and Some Findings. J. Consumer Research 13 (December 1986): 357-73.

Burstein, M. L., The Economics of Tie-In Sales. Rev. Economics and Statistics 42 (February 1960): 68-73.

Das, Priya R., Semantic Cues and Buyer Evaluation of Promotional Communication, Robert P. Leone and V. Kumar (eds.) 1992 AMA Educators' Proceedings: Enhancing Knowledge Development in Marketing. Chicago: American Marketing Association, 1992: 12-17.

Della Bitra, Albert J., Monroe, Kent B., and McGinnis, John M., Consumer Perceptions of Comparative Price Advertisements. J. Marketing Research 18 (November 1981): 416-427.

Demsetz, Harold, The Cost of Transacting. Q. J. Economics 82, (February 1968): 33-35.

Desarbo, Wayne S., Rao, Vithala R., Steckel, Joel H., Wind, Jerry, and Colombo, Richard, A Friction Model for Describing and Forecasting Price Changes. Marketing Science, 6 (Fall 1987): 299-319.

Dolan, Robert J., Managing the Pricing of Service-Line and Service-
Line Bundles. In Competing in a Deregulated or Volatile Market, Lauren K. Wright (ed.), MSI Report No. 87-1111 (December 1987).

Drumwright, Minette, A Demonstration of Anomalies in Evaluations of Bundling. Marketing Letters, 3, (November 1992): 311-322.

Foster, Irene Raj, The Cross-Couponing of Complements, Substitutes and Unrelated Goods, unpublished working paper, Vanderbilt University, Nashville, 1992.

Gabor, Andre, and Granger, Clive, Price Sensitivity of the Consumer. J. Advertising Research 4 (1964): 40-44.

Gaeth, Gary J., Levin, Irwin P., Chakraborty, Goutam, and Levin, Aron M., Consumer Evaluation of Multi-Product Bundles: An Information Integration Analysis. Marketing Letters 2 (December 1990): $47-57$.

Green, Paul E., and Devita, Michael T., A Complementary Model of Consumer Utility for Item Collections. J. Consumer Research 1 (December 1974): 56-67.

Green, Paul E., and Wind, Yoram, Conjoint Analysis of Price Premiums for Hotel Amenities. J. Business 57, (1984): 111-132.

Green, Paul E., Wind, Yoram, and Jain, Aran K., Preference Measurement of Item Collections. J. Marketing Research 9 (November 1972): 371-377.

Guiltinan, Joseph P., The Price Bundling of Services: A Normative Framework. J. Marketing 51 (1987): 74-85.

Hanson, Ward, and Martin, R. Kipp, Optimal Bundle Pricing. Management Science 36 (February 1990): 155-176

Hoch, Steven J., and Ha, Young-Won, Consumer Learning and the Ambiguity of Product Experience. J. Consumer Research 13, (September 1986): 221-233.

Kahn, Barbara E., and Louie, Therese A., The Effects of Retraction of Price Promotions and Brand Choice Behavior for Variety-seeking and Last-Purchase Loyal Customers. J. Marketing Research 27 (August 1990): 279-289.

Kahn, Barbara E., and Raju, Jagmohan S., The Effects of Price Promotions on Variety-seeking and Reinforcement Behavior. Marketing Science 10 (1991): 316-337.

Kahneman, Daniel, and Tversky, Amos, Prospect Theory: An Anaylsis of Decision Under Risk. Econometrica 47 (March 1979): 263-291.

Kaicker, Ajit, and Bearden, William O., Product Bundling and Consumer Perceptions of Value: Tests Across Alternative Purchase Scenarios. Working Paper at Valdosta State College. 1993.

Karlinsky, Meir, and Farquar, Peter H., Context Effects in Price Bundling, unpublished working paper presented at the Association of Consumer Research Conference in Honolulu, Hawaii in October, 1988.

Krishna, Aradhna, Effects of Dealing Patterns on Consumer Perceptions of Deal Frequency and Willingness to Pay. J. Marketing Research 28 (November 1991): 441-451

McAfee, Preston R., McMillan, John, and Whinston, Michael D., Multiproduct Monopoly, Commodity Bundling, and Correlation of Values. J. Economics 103 (August 1989): 371-383.

Mazumdar, Tridib, and Jun, Sung Youl, Consumer Evaluations of Changes in Bundle and Component Prices, Working paper at Syracuse University. 1992.

Meyer, Robert J., and Assuncao, Joao, The Optimality of Consumer Stockpiling Strategies. Marketing Science 9 (Winter 1990): 18-41.

Monroe, Kent B., Measuring Price Thresholds by Psychophysics and Latitudes of Acceptance. J. Marketing Research 8 (November 1971): 460-464.

Nagle, Tom. The Strategy and Tactics of Pricing. Englewood Cliffs, NJ: Prentice-Hall. 1987 
Puto, Christopher, The Framing of Buying Decisions. J. Consumer Research 14 (December 1987): 301-315.

Schmalensee, Richard, Gaussian Demand and Commodity Bundling. J. Business 57 (January 1984): 211-230.

Sherif, M., and Hovland, C., Social Judgment. New Haven, CI: Yale University Press. 1961.

Simonson, Itamar, and Winer, Russell. The Influence of Purchase Quantity and Display Format on Consumer Preference for Variety. J. Consumer Research 19 (June 1992):133-138.

Stigler, George J., A Note on Block Booking. In George J. Stigler, ed., The Organization of Industry, Homewood, IL: Richard D. Irwin. 1968

Sujan, Mita, Consumer Knowledge: Effects on Evaluation Strategies Moderating Consumer Judgments. J. Consumer Research 12 (June 1985): $31-46$.

Telser, L. G., A Theory of Monopoly of Complementary Goods. J. Business 52 (1979): 211-230.
Thaler, Richard, Mental Accounting and Consumer Choice. Marketing Science 2 (Summer 1983): 199-214.

Tversky, Amos, and Kahneman, Daniel, Judgment Under Uncertainty: Heuristics and Biases. Science 185 (1974): 1124-1131.

Yadav, Manjit, and Monroe, Kent B., How Buyers Perceive Savings in a Bundle Price: An Examination of a Bundle's Transaction Value. J. Marketing Research 30 (August 1993), 350-358.

Yadav, Manjit S., and Grewal, Dhruv, An Examination of Buyer's Internal Reference Prices and Transaction Value in Bundle Offers, presented at 1993 AMA Winter Conference, Newport Beach, CA. 1993.

Wilson, Lynn O., Weiss, Allen M., and John, George, Unbonding of Industrial Systems, J. Marketing Research 27 (May 1990), 123-138. 